the second cycle. Socio-demographic, personal characteristics and life habits were collected. LBP was assessed using the Nordic musculoskeletal health questionnaire. The impact of low back pain was assessed using the Oswestry disability index (ODI). Results: One hundred and seventy-nine students were included. The mean age was $22.9 \pm 2.3$ years [19.64-38.21]. The sex ratio was 0.29 . The average body mass index was $23.55 \pm 4.22 \mathrm{~kg} / \mathrm{m} 2$ [17.67-43.07]. $82 \%$ of the students were in the second cycle of medical studies. $26.4 \%$ of the students had a regular sports activity. $91.2 \%$ spent more than 4 hours a day in a sitting position. The point, annual, and lifetime prevalence of LBP among medical students was $41.2 \%, 80.4 \%$ and $90.6 \%$, respectively. Low back pain was acute in more than $58.8 \%$, subacute in $14.9 \%$ and chronic in $26.3 \%$. The mean ODI score was $10.32 \% \pm 8.48 \%$ [0-32\%]. Students with LBP were significantly younger than students without LBP $(p=0.015)$. LBP was more common in students who spent more than 4 hours in a sitting position with a difference at the limit of significance $(p=0.059)$. Being in the 2 nd cycle was significantly associated with the occurrence of LBP $(p=0.006)$. Poor screen projection in the amphitheater was significantly associated with the occurrence of LBP $(p=0.029)$. We found a statistically very significant relationship between the occurrence of LBP and the poor layout of the amphitheaters $(p=0.000)$. The feeling of depression was significantly higher among LBP students $(p=0.018)$. Feelings of fatigue, being overwhelmed, irritability and worry were more frequently found in LBP students, but this difference was not statistically significant. In a multivariate analysis, the only factors that remained statistically significant were feeling of depression $(p=0.046, \mathrm{OR}=3.88 ; \mathrm{Cl}=[1,3-11,55])$ and the poor layout of the amphitheaters $(p=0.006, \mathrm{OR}=8.99 ; \mathrm{Cl}=[2.55-31.69])$.

Conclusion: The annual prevalence of LBP was $80.4 \%$. These results testify to the magnitude of this health problem. The factors associated to LBP seemed to be essentially modifiable factors. This encourages special attention from medical schools to increase students' awareness of low back pain and to provide appropriate measures at reduce this musculoskeletal disorder.

Disclosure of Interests: None declared

DOI: 10.1136/annrheumdis-2020-eular.6299

\section{AB0963 HOW OFTEN DO DOCTORS TREAT PATIENTS WITH LOCAL DAMAGE TO THE PERIARTICULAR SOFT TISSUES IN REAL CLINICAL PRACTICE?}

A. Karateev ${ }^{1}$, A. Lila ${ }^{1}$, N. Zagorodniy ${ }^{2}$, E. Pogozheva ${ }^{1} .{ }^{1}$ Nasonova Research Institute of Rheumatology Moscow, Moscow, Russian Federation; ${ }^{2}$ Priorov National Medical Research Center of Traumatology and Orthopedics, Moscow, Russian Federation

Background: Damage of the periarticular soft tissues (DPST) - tendinitis, entesitis, bursitis, etc. are one of the most common reasons for patients to contact rheumatologists and orthopedic surgeons.

Objectives: To evaluate the frequency and localization of DPST in real clinical practice, as well as the effectiveness of therapy for this pathology in the acute period.

Methods: 68 outpatient orthopaedic surgeons evaluated the frequency of initial patient recourse due to DPST within one month. The study did not include patients with systemic rheumatic diseases such as spondyloarthritis. The localization of DPST and the dynamics of clinical manifestations were evaluated in 1227 patients (women $42.5 \%$, cf. age $51.3 \pm 15.5$ years). Non-steroidal anti-inflammatory drugs (NSAIDs), mainly meloxicam, were used as a first-line treatment for DPST. The results of treatment were evaluated after 10-14 days with repeated visits of patients.

Results: 7766 cases of primary outpatient treatment by orthopedic surgeons were evaluated. DPST was the cause of treatment in $1227(15.8 \%)$ patients. This was the third highest incidence after acute injuries $(37.2 \%)$ and knee osteoarthritis $(20.6 \%)$

In patients with DPST, the most common lesions were in the knee area (knee entesopathy, prepatellar bursitis, pes anserinus area tendinitis/bursitis) $-21.2 \%$, the foot (plantar fasciitis) $-16.9 \%$, the shoulder (tendinitis of the rotator cuff) $-16.4 \%$, and the elbow (lateral and medial epicondylitis) - 15.3\%. After treatment, there was a significant decrease in the severity of pain during movement - from $6.58 \pm 1.61$ to $2.48 \pm 1.60$ points on the numerical rating scale $(p<0.001)$, a decrease in the intensity of pain at rest, at night and during palpation, as well as the severity of functional disorders. The need for local injection of glucocorticoids occurred in $22.1 \%$ of patients. Significant improvement was observed in all DPST localities, with $68.1 \%$ of patients rating the treatment result as "good" and "excellent". Adverse reactions were observed in $15.0 \%$ of patients, and no serious complications were reported.

Conclusion: DPST is the third most frequent reason of recourse to a doctor after acute injuries and osteoarthritis of large joints in the practice of outpatient orthopedic surgeons. The use of NSAIDs in the maximum therapeutic dose for 10-14 days allows for significant improvement in DPST of different localization.

Disclosure of Interests: None declared

DOI: 10.1136/annrheumdis-2020-eular.3969

\section{AB0964 THE ASSOCIATION BETWEEN RESIDUAL SYMPTOMS AND CERVICAL SPINE LESIONS IN RHEUMATOID ARTHRITIS}

T. Kashiwagura ${ }^{1}$, M. Kobayashi ${ }^{2}$, Y. Sugimura ${ }^{3}$, T. Kawano ${ }^{4}$, H. Sato ${ }^{5}$, N. Miyakoshi ${ }^{4}$, Y. Shimada ${ }^{4}$ on behalf of AORA Akita orthopedic group on Rheumatoid Arthritis. ${ }^{1}$ Akita City Hospital, Akita, Japan; ${ }^{2}$ Hiraka General Hospital, Yokote, Japan; ${ }^{3}$ Nakadori General Hospital, Akita, Japan; ${ }^{4}$ Akita University Graduate School of Medicine, Akita, Japan; ${ }^{5}$ Kita Akita Municipal Hospital, Kita Akita, Japan

Background: Treatment outcomes in rheumatoid arthritis (RA) have been improved with advances in drug therapy. In daily clinical practice, the outcomes are assessed based on the presence of swollen or tender joints, global assessment using a visual analog scale by a patient (GVAS) and a physician (DrVAS), etc., in addition to inflammatory findings. Although inflammation and joint symptoms are suppressed, many patients show no improvement in GVAS scores. The reported residual RA symptoms include morning stiffness (MS), pain (P), and dullness (D), but their causes are not completely known. Latent cervical spine lesions sometimes exist in RA, but their association with residual RA symptoms is unknown.

Objectives: We examined cervical spine lesions and residual symptoms in patients with RA who achieved the therapeutic goal.

Methods: Of 124 patients with RA, 82 ( 25 men and 57 women) who achieved a low disease activity (LDA) state on the Disease Activity Score for 28 joints with erythrocyte sedimentation rate (DAS28-ESR) were included. The mean age was 65.7 (28- 83) years, and the disease stage was Stage I in 28 patients, Stage II in 14, Stage III in 13, and Stage IV in 27. Dysfunction was graded as Class 1 in 63 patients, Class 2 in 18, and Class 3 in one (Steinbrocker classification). Biopharmaceuticals had been administered in 27 patients. As for disease activity, the DAS28-ESR scores indicated complete remission in 54 patients and LDA in 28. The survey form was used to investigate the presence or absence/duration of MS, the presence or absence/severity of $P$ (Pain VAS), and the presence or absence/severity of D (Dullness VAS). On lateral functional radiographs of the cervical spine, patients with spinal lesions were selected and divided into the asymptotic stability (ASS; atlantoaxial dislocation $\geq 3 \mathrm{~mm}$ ) + vertical setting (VS; Ranawat value $<13 \mathrm{~mm}$ ) group, the cervical spondylolisthesis group ( $\geq 3 \mathrm{~mm}$ of slippage on dynamic radiographs), and the spondylolisthesis group ( $\geq 3 \mathrm{~mm}$ of slippage on dynamic radiographs). They were examined for association with residual symptoms.

Results: According to cervical spine lesions, the patients who achieved the therapeutic goal were divided into the ASS+VS group comprising 15 patients (18.3\%), the spondylolisthesis group comprising 11 (13.4\%), and the stenosis group comprising $18(22.0 \%)$. Among them, only the spondylolisthesis group showed significant differences in residual RA symptoms. In the spondylolisthesis group, the disease duration was longer, but there was no difference in age. MS, $\mathrm{P}$, and $\mathrm{D}$ were significantly severer. The duration of MS was longer, and both Pain and Dullness VAS scores were higher. The score on each component of the DAS28 showed no difference in inflammatory findings. GVAS and DrVAS scores were higher. No common perceptions of spinal symptoms were shared between any patients with cervical spine lesions and physicians.

Conclusion: Improved patient-reported outcomes (PROs) are considered to be important to achieve more complete remission. There are various reports on the causes of residual RA symptoms, but many aspects remain unknown. Based on the results of this study, because asymptomatic subaxial subluxation is one of concerns in patients with spondylolisthesis with dynamic instability of the cervical spine, cervical spine diseases should also be considered in patients with severe residual symptoms. Not only radiography but also magnetic resonance imaging needs to be performed.

Acknowledgments: The authors wish to acknowledge Miss Sasaki

Disclosure of Interests: None declared

DOI: 10.1136/annrheumdis-2020-eular.3658

\section{AB0965 \\ EVALUATION OF THE IMPACT OF THE JOB STRESS ON THE ONSET OF MUSCULOSKELETAL DISORDERS IN THE HEALTHCARE WORKERS OF THE GENERAL HOSPITAL OF DOUALA, CAMEROON}

F. Kemta Lekpa ${ }^{1}$, M. N. Hugo Bertrand ${ }^{2} .{ }^{1}$ University of Dschang, Dschang, Cameroon; ${ }^{2}$ Douala General Hospital, Douala, Cameroon

Background: Job stress (workload) and its repercussions on health have already been described. However, very few publications has been performed in sub-Saharan Africa.

Objectives: To assess the link between job stress and musculoskeletal disorders (MSD) among healthcare workers of the Douala General Hospital.

Methods: In this cross-sectional study, the job stress, evaluated according to the Karasek model, made it possible to measure job-strain (high psychological 
demand and low decision-making latitude), iso-strain (job-strain and lack of social support), and low-strain (relaxed or low-load work).

Results: Among the 261 participants in the study, $67.43 \%$ were women. The average age was $39.80 \pm 9.4$ years. The average length of professional service was $8.91 \pm 7.30$ years [ 1 - 35 years].

Regarding the job stress, $65.14 \%$ of the healthcare workers followed at least 11 patients per day. $78.54 \%$ had more than 40 hours of weekly work and $46.36 \%$ carried heavy loads during work. Job-strain was found in $58.62 \%$ of the participants, iso-strain in $7.66 \%$ and low-strain in $5.36 \%$. MSDs were described by 225 participants $(86.21 \%)$. They were mainly low back pain $(68.44 \%)$, neck pain $(52 \%)$ and shoulders' pain $(37.78 \%)$.

In multivariate analysis, only weekly work> 40 hours (OR $=2.59 ; 95 \% \mathrm{Cl}$ $1.11-6.02, p=0.026)$ and job-strain $(\mathrm{OR}=3.14 ; 95 \% \mathrm{Cl} 1.33-7.39, \mathrm{p}=0.009)$ remained associated with the presence of MSD.

Conclusion: The healthcare workers in our study are exposed to a high psychological and physical job stress, causing MSDs. Ergonomic programs should be designed for these workers.

Disclosure of Interests: None declared

DOI: 10.1136/annrheumdis-2020-eular.5857

\section{AB0966 PREVALENCE OF SARCOPENIA IN PATIENTS WITH RHEUMATOLOGICAL DISEASES}

Y. Lavrishcheva ${ }^{1}$, A. Jakovenko ${ }^{2}{ }^{1} 1$ Almazov National Medical Research Centre, Saint Petersburg, Russian Federation, Saint Petersburg, Russian Federation; ${ }^{2}$ Pavlov First Saint Petersburg State Medical University, Saint Petersburg, Russian Federation, Saint Petersburg, Russian Federation

Background: The presence of sarcopenia in rheumatological patients is an independent predictor of morbidity and mortality in this cohort of patients. Patients with sarcopenia are characterized by lower physical activity, a tendency to depression and poor social adaptation.

Objectives: To assess the prevalence of sarcopenia in rheumatological patients. Methods: 317 patients were examined, including 79 with systemic lupus erythematosus, 98 with rheumatoid arthritis, 72 with systemic scleroderma, 68 with spondyloarthritis. Among them, 201 women and 116 men, the age of patients ranged from 21 to 58 years, the average age at the time of inclusion of patients in the study was $41.1 \pm 7.3$ years. Sarcopenia was diagnosed using the method recommended by The European Working Group on Sarcopenia in Older People2.

Results: The frequency of occurrence of a decrease in the total mass of skeletal muscle according to the skeletal muscle mass index (ISMM) was 31.2\% (99 patients), a decrease in muscle strength according to the wrist dynamometry was observed in $44.5 \%$ (141 patients), low skeletal muscle performance according to the results $\mathrm{NIH}$ Toolbox 4 Meter Walk Gait Speed Test in 42.8\% (135 patients). The prevalence of suspected sarcopenia (probable sarcopenia) was 13.3\% (42 patients) and sarcopenia 31.2\% (99 patients), no cases of severe sarcopenia were detected. Statistically significant differences were obtained between groups of patients depending on the duration of rheumatological disease and the prevalence of sarcopenia $(x 2=19.328 p=0.001)$.

Conclusion: The prevalence of sarcopenia in rheumatological patients in the general population was $31.2 \%$.

Disclosure of Interests: None declared

DOI: 10.1136/annrheumdis-2020-eular.1885

\section{AB0967 $\quad$ OBESITY IMPACTS SURGICAL REPAIR OF ROTATOR CUFF TEAR IN A LOW-INCOME POPULATION}

C. Silva ${ }^{1}$, N. Mourão ${ }^{1}$, J. Landim², L. Da Rocha ${ }^{2}$, M. Lacerda ${ }^{1}$, A. Rocha ${ }^{2} .{ }^{1}$ Hospital Geral De Fortaleza, Fortaleza, Brazil; ${ }^{2}$ Faculty of Medicine - Federal University of Ceará, Internal Medicine, Fortaleza, Brazil

Background: Rotator cuff tears (RCT) rank high among causes of shoulder pain in primary care. Surgical repair of RCT is indicated when judged refractory to clinical treatment. Comorbidities and environmental issues may impact the surgical result of $\mathrm{RCT}$ repair.

Objectives: to determine the impact of Obesity and Smoking in the outcome of low-income patients subjected to RCT repair.

Methods: Low-income ( $<5500,00$ US\$ annual pib per capta*) patients living in Fortaleza-CE, Brazil were prospectively (2016-2018) evaluated in the Orthopedic and Rheumatology Services of the Hospital Geral de Fortaleza. Demographics and clinical data focusing Obesity (BMI $>/ \leq 30$ ) and Smoking status (present/absent) were registered. Pain $(0-10 \mathrm{~cm}$ VAS) and functional shoulder score evaluation by the University of California at Los Angeles Shoulder Score (UCLA) and American Shoulder and Elbow Surgeons (ASES) scoring systems following at least 2 years post-operative follow-up were recorded.

Results: Thirty-nine individuals, $60.9 \pm 7.1$ years-old, 30 female $(68.3 \%)$ with $5.1 \pm 1.9$ years follow-up were evaluated; $21(44.7 \%)$ were Smokers and $12(25.5 \%)$ Obese $(\mathrm{BMI}>30)$. Other comorbidities included 16 arterial hypertension, 18 dyslipidemia, 17 osteoarthritis, 4 rheumatoid arthritis, 1 gout. Pain VAS values were $5.1 \pm 2.6$ vs $3.1 \pm 2.8$ in Obese vs Non-Obese $(p=0.03)$ and $4 \pm 2.8$ vs $3.37 \pm 2.99$ in Smokers vs Non-Smokers ( $p=0.26$ ), respectively. UCLA was $22.4 \pm 8.2$ vs. $28.79 \pm 5.6$ in
Obese vs Non-Obese $(p=0.004)$ and $26.2 \pm 6.5$ vs. $27.75 \pm 7.18(p=0.25)$ in Smokers vs. Non-smokers, respectively. ASES was $47.89 \pm 28.3$ vs. $68.1 \pm 25.78(p=0.021)$ in Obese vs. Non-obese and $58.98 \pm 26.69$ vs $65.3 \pm 28.1 \quad(p=0.243)$ in Smokers vs Non-Smokers, respectively.

Conclusion: Using Patient Reported Outcome instruments, these long-term data show that Obesity negatively impacts the outcome of surgical repair of RCT in low-income patients. Smoking status was apparently irrelevant but the number of cigarettes smoked daily was not considered. Emphasis on weight reduction is a practical, affordable though hard to implement measure that could improve surgical results when repairing RCT.

References: *https://pt.wikipedia.org/wiki/Lista_de_munic\%C3\%ADpios_do Brasil_por_PIB

Disclosure of Interests: Christine Silva: None declared, Natalia Mourão: None declared, Joaquim Landim: None declared, Leila da Rocha: None declared, Marco Lacerda: None declared, Airton Rocha Speakers bureau: Not related to the present work

DOI: 10.1136/annrheumdis-2020-eular.3128

AB0968

DIAGNOSIS OF INFLAMMATORY BACK PAIN (IBP) IN A LOW-INCOME POPULATION USING ASAS IBP DEFINITION

J. Oliveira ${ }^{1}$, R. Nunes ${ }^{1}$, G. Da Silva ${ }^{1}$, I. Nogueira ${ }^{1}$, A. Azevedo ${ }^{1}$, X. Baraliakos ${ }^{2}$, A. Rocha ${ }^{1}$. ${ }^{1}$ Faculty of Medicine - Federal University of Ceará, Fortaleza, Brazil; ${ }^{2}$ Rheumazentrum Ruhrgebiet, Herne, Berlin, Germany

Background: Inflammatory back pain (IBP) is an important entry criterion for identify ing patients with axial spondyloarthritis. Due to the very frequent prevalence of chronic non-inflammatory back pain (CBP), IBP is difficult to differentiate and recognize in many clinical practices. CBP is a frequent diagnosis in populations with low socioeconomic status.

Objectives: To investigate whether IBP ASAS definition help discriminate from CBP in a low-income population.

Methods: A total of 202 consecutive individuals were directly interviewed in Fortaleza/ Brazil, for the prevalence of IBP (ASAS definition), monthly family income (US\$), school education $[>/ \leq 8$ school-years(SY)], and smoking habit (present/absent). People from all social levels were included.

Results: Mean age was $38.9 \pm 12.9$ years, 100 (49.5\%) were male and $36(17.8 \%)$ were smokers; $135(66.8 \%)$ declared less than 730 US\$ family earnings per month and $71(35.1 \%)$ had less than 8 SY. Although 122 (60.3\%) declared lumbar pain, in comparison, 29 (14.3\%), 22 (10.9\%) and 59 (29.2\%) fulfilled ASAS, Berlin, and Calin's IBP criteria, respectively. There were $39(58.02 \%)$ vs. $83(61.5 \%)$ with vs. without CBP and $9(13.4 \%)$ vs. 20 (14.8\%) fulfilling vs. not fulfilling the ASAS IBP definition among those with more or less than 730US $\$$ earnings $(P>0.05)$, respectively.

Conclusion: This is the first report on the prevalence of IBP in a very low-income population. Over one-third had less than $8 S Y$, revealing very low literacy. Smoking prevalence was also low if compared to $28 \%$ smoking prevalence WHO estimates across Europe*. These IBP prevalence data are similar to those reported in wealthier populations, living in higher latitude. Data suggest that ASAS IBP definition may be used to discriminate patients with IBP from those with CBP, regardless of income and literacy. References: This is the first report on the prevalence of IBP in a very low-income population. Over one-third had less than 8SY, revealing very low literacy. Smoking prevalence $(17.8 \%$ ) was also low if compared to $28 \%$ smoking prevalence WHO estimates across Europe*. These IBP prevalence data are similar to those reported in wealthier populations, living in higher latitude. Data suggest that ASAS IBP definition may be used to discriminate patients with IBP from those with CBP, regardless of income and literacy.

Disclosure of Interests: Jobson Oliveira: None declared, Rodolfo Nunes: None declared, Guilherme da Silva: None declared, Igor Nogueira: None declared, Artur Azevedo: None declared, Xenofon Baraliakos Grant/research support from: Grant/ research support from: AbbVie, BMS, Celgene, Chugai, Merck, Novartis, Pfizer, UCB and Werfen, Consultant of: AbbVie, BMS, Celgene, Chugai, Merck, Novartis, Pfizer, UCB and Werfen, Speakers bureau: AbbVie, BMS, Celgene, Chugai, Merck, Novartis Pfizer, UCB and Werfen, Airton Rocha Speakers bureau: Not related to the present work

DOI: 10.1136/annrheumdis-2020-eular.4260

\section{AB0969}

GAINED WEIGHT DURING PREGNANCY AND LOW BACK PAIN: IS IT REALLY ASSOCIATED?

M. Yasmine ${ }^{1}$, S. Miladi ${ }^{1}$, A. Fazaa ${ }^{1}$, L. Souebni ${ }^{1}$, S. Mariem ${ }^{1}$, K. Ouenniche ${ }^{1}$ S. Kassab ${ }^{1}$, S. Chekili ${ }^{1}$, K. Ben Abdelghani ${ }^{1}$, A. Laatar ${ }^{1} .{ }^{1}$ Mongi Slim Hospital, Tunis, Tunisia

Background: Back pain is known to be a common complaint during pregnancy explained by gained weight in this period. Besides, the incidence of low back pain (LBP) in postpartum has also been quoted to be non-negligible even after delivery.

Objectives: The aim of our study was to assess if the development of LBP during the post-partum period was correlated to gained weight after delivery. 